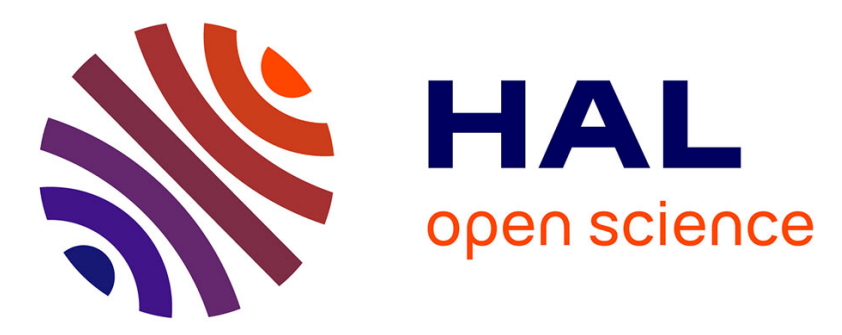

\title{
Space charge distribution synthesis by multiphysics simulation: application to the PWP techniques
}

Olivier Gallot-Lavallée, J.-L. Reboud

\section{To cite this version:}

Olivier Gallot-Lavallée, J.-L. Reboud. Space charge distribution synthesis by multiphysics simulation: application to the PWP techniques. CEIDP, 2007, Canada. pp.780-3. hal-00182591

\section{HAL Id: hal-00182591 \\ https://hal.science/hal-00182591}

Submitted on 26 Oct 2007

HAL is a multi-disciplinary open access archive for the deposit and dissemination of scientific research documents, whether they are published or not. The documents may come from teaching and research institutions in France or abroad, or from public or private research centers.
L'archive ouverte pluridisciplinaire HAL, est destinée au dépôt et à la diffusion de documents scientifiques de niveau recherche, publiés ou non, émanant des établissements d'enseignement et de recherche français ou étrangers, des laboratoires publics ou privés. 


\title{
Space charge distribution synthesis by multiphysics simulation: application to the PWP techniques
}

\author{
O. Gallot-Lavallée, J-L. Reboud \\ Grenoble Electrical Engineering lab, Joseph Fourier University \\ c/o CNRS, 25 Rue des Martyrs \\ 38042 Grenoble, France
}

\begin{abstract}
Initially we have implemented a model based on the Finite Element Method (FEM). This model consist in simulate experiments of space charge measurement: the principle of the various experiments consists in forcing the displacement of space charge by a pressure wave, temperature gradient or an electric excitation, and measuring the transitory current thus created at the boundaries of material or the sound emission associated to the generated movement. In this article, we propose an alternative to the traditional exploitation of the Pressure Wave Propagation techniques, based on a quasi-random approach of the space charge distribution by bringing together of the electric answers (experimented and simulated). Adopted methodology consists has to seek a space charge distribution, such as the simulated electric answer reaches a certain similarity with the experimentation. One shows as well as the space charge distribution can be obtained in a completely reversed way. Indeed this new methodology consists in finding the space charge distribution which gives a simulated electric answer nearest to that measured.
\end{abstract}

\section{INTRODUCTION}

In a precedent study [1], we proposed the use of a numerical model to simulate the measurement of space charge by propagation of a pressure wave on composites polymers [2]. Numerical simulations were performed with the SYSTUS $®$ multiphysics software, developed by ESI Group. As first test case, we compared our simulation with the measurements obtained starting from a method based on relative displacement: the LASER induced pressure pulse method. This method is based on relative displacement; it consists in forcing the displacement of space charge compared to the electrodes creating by total influence a transient of charges in the electrodes. In practice, it's the luminous energy absorption by a target (for example a layer of Indian ink) deposited on the surface of the material which causes a brutal rise in temperature and thus a dilation of this layer creating a pressure wave on both sides [3].

In this article, we present an alternative to the traditional exploitation of the Pressure Wave Propagation techniques, based on a quasi-random approach of the space charge distribution by bringing together of the electric answers (experimented and simulated).

We will first of all point out the principal characteristics of the electro-mechanical uncoupled model build to simulate a PWP measurement. Then we will detail the algorithm allowing to find a space charge distribution representative of the awaited electrostatic phenomenon. And finally, we will discuss the limits of this approach.

\section{Electro-MecANiCAL MODEL}

\section{A. Geometrical (reminder)}

Simulations are carried out on the basis of two-dimensional geometrical model Fig. 1. The model is however equipped with an additional dimension along Z-axis in particular used during the surface calculation of charge density. The pressure wave is directly applied in entry of cathode. The substrate absorbing LASER beam is thus not modeled. The wave is propagated along $\mathrm{X}$-axis and crosses successively the cathode $(\mathrm{K})$, the dielectric (D) and finally the anode (A). The mesh is regular within the three systems $\mathrm{A}, \mathrm{D}$ and $\mathrm{K}$ and comprises only on cell along $\mathrm{Y}$-axis (see Table 1).

TABLE I

GEOMETRICALS PARAMTERS

\begin{tabular}{|l|l|c|c|c|}
\hline Symbol & \multicolumn{1}{|c|}{ Name } & Value & Unity \\
\hline $\mathrm{H}_{\mathrm{e}}$ & Deepness & $\mathrm{e}$ & 3.8 & $10^{-3} \mathrm{~m}$ \\
\hline $\mathrm{H}_{\mathrm{d}}$ & Deepness & $\mathrm{d}$ & 0.5 & $10^{-3} \mathrm{~m}$ \\
\hline $\mathrm{Z}_{\mathrm{e}}$ & Width & $\mathrm{e}$ & 10 & $10^{-3} \mathrm{~m}$ \\
\hline $\mathrm{Z}_{\mathrm{d}}$ & Width & $\mathrm{d}$ & 10 & $10^{-3} \mathrm{~m}$ \\
\hline
\end{tabular}

$\mathrm{d}$ : stand for dielectric, e for electrode and $\mathrm{m}$ for Mechanical.

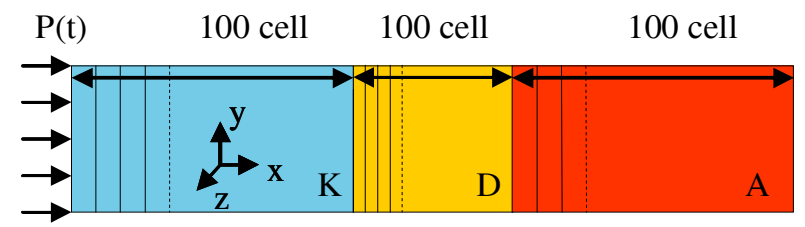

Fig. 1. Two-dimensional model used for simulation. The pressure wave is propagated along $\mathrm{X}$-axis from cathode to anode while passing by the dielectric one. The meshing is regular. The following boundary conditions are assumed: the plan of exit is blocked according to $\mathrm{X}$ and $\mathrm{Y}$ directions and the side plans are blocked according to $\mathrm{Y}$.

\section{B. Mechanical (reminder)}

The entry pressure wave is uniform along the $\mathrm{Y}$-axis transverse with the wave propagation. The boundary conditions are such as: the side edges are blocked according to $\mathrm{Y}$; the edge of exit is blocked according to $\mathrm{X}$ and $\mathrm{Y}$. The traditional visco-elastic properties are assigned to the dielectric and the electrodes in an isotropic way. The principal mechanicals parameters of the model of simulation are pointed out (see Table 2). 
TABLE II

MECHANICALS PARAMTERS

\begin{tabular}{|c|c|c|c|c|}
\hline Symbol & \multicolumn{2}{|l|}{ Name } & Value & Unity \\
\hline$\rho_{\mathrm{me}}$ & Density & $\mathrm{e}$ & 2.3 & $10^{3} \mathrm{~kg} / \mathrm{m}^{3}$ \\
\hline$\rho_{\mathrm{md}}$ & Density & $\mathrm{d}$ & 1.2 & $10^{3} \mathrm{~kg} / \mathrm{m}^{3}$ \\
\hline $\mathrm{v}_{\mathrm{e}}$ & Sound velocity & $\mathrm{e}$ & 5700 & $\mathrm{~m} / \mathrm{s}$ \\
\hline $\mathrm{v}_{\mathrm{d}}$ & Sound velocity & $\mathrm{d}$ & 2400 & $\mathrm{~m} / \mathrm{s}$ \\
\hline $\mathrm{E}_{\mathrm{me}}$ & Young modulus $E_{m e}=\rho_{m e} v_{e}{ }^{2}$ & $\mathrm{e}$ & 75 & $10^{9} \mathrm{~kg} / \mathrm{m} . \mathrm{s}$ \\
\hline $\mathrm{E}_{\mathrm{md}}$ & Young modulus $E_{m d}=\rho_{m d} v_{d}{ }^{2}$ & $\mathrm{~d}$ & 7.0 & $10^{9} \mathrm{~kg} / \mathrm{m} . \mathrm{s}$ \\
\hline $\mathbf{v}_{\text {me }}$ & Poisson coefficient & $\mathrm{e}$ & 0.27 & 1 \\
\hline $\mathbf{v}_{\mathrm{md}}$ & Poisson coefficient & $\mathrm{d}$ & 0.30 & 1 \\
\hline $\mathrm{Z}_{\mathrm{e}}$ & Acoustic impedance (cf annex) & $\mathrm{e}$ & 13 & $10^{6} \mathrm{~kg} / \mathrm{m}^{2} / \mathrm{s}$ \\
\hline $\mathrm{Z}_{\mathrm{d}}$ & Acoustic impedance (cf annex) & $\mathrm{d}$ & 2.9 & $10^{6} \mathrm{~kg} / \mathrm{m}^{2} / \mathrm{s}$ \\
\hline $\mathrm{Ai}$ & \multicolumn{2}{|l|}{ Pressure wave Gaussian amplitude } & 30 & $10^{5} \mathrm{~kg} / \mathrm{m}^{2}$ \\
\hline$\Delta \mathrm{t}$ & \multicolumn{2}{|l|}{ Pressure wave passage time $(1 / 2)$} & 10 & $10^{-12} \mathrm{~s}$ \\
\hline$\alpha_{\mathrm{d}}$ & \multicolumn{2}{|l|}{ Dampening (rigidity) } & 0.51 & $10^{-9} \mathrm{~s}^{-1}$ \\
\hline$\beta_{d}$ & \multicolumn{2}{|l|}{ Dampening (mass) } & 0.50 & $10^{6} \mathrm{~s}^{-1}$ \\
\hline
\end{tabular}

$\mathrm{d}$ : stand for dielectric, e for electrode and $\mathrm{m}$ for mechanical.

\section{Electrical (reminder)}

It is considered that the topology reproduce a system in total influence. Electrostatic pressure, permittivity dependence and thermal are neglected. The calculation of current is carried out according to the "Maxwell Ampere" equation simplified with the studied case i.e. magnetic induction B is neglected. All in all, the equation of the current density is governed by the following relation (1).

$$
j=-\frac{\partial D}{\partial t}
$$

Simulation allowing us to obtain directly the electrical potential distribution of the system during the pressure wave propagation, we exploit (1) while revealing in (3) the field and the electrical current. Calculation is carried out at the border between the dielectric one and the anode on the surface of contact S.

$$
\begin{array}{r}
D=\varepsilon_{0} \cdot \varepsilon_{\mathrm{r}} \cdot \mathrm{E} \\
\Rightarrow \mathrm{i}(\mathrm{t})=-\varepsilon_{0} \cdot \varepsilon_{\mathrm{r}} \cdot \int_{\mathrm{s}} \frac{\partial \mathrm{E}}{\partial \mathrm{t}} \cdot \mathrm{ds}
\end{array}
$$

Numerical calculation (4) is thus based on (3), where $\mathrm{H}$ represents the thickness of the system following $\mathrm{Z}$ making it possible to calculate the surface of contact and 1 the length (according to Y) of a basic cell. Here, numerical calculation is carried out the unique cell located at the border of the interface insulator-anode.

$$
\Rightarrow \mathrm{i}(\mathrm{t})=-\varepsilon_{0} \varepsilon_{\mathrm{r}} \cdot 1 \cdot \mathrm{H} \cdot \frac{\mathrm{E}(\mathrm{t})-\mathrm{E}(\mathrm{t}-1)}{\Delta \mathrm{t}}
$$

\section{AlgORITHM}

Once defined the electro-mechanical and geometrical object properties (Electrode - Dielectric - Electrode), the method consists in simulating each electric response of the object stressed by a pressure wave and filled with an elementary density of space charge per cell. Then the aim of this program is to find a linear combination allowing fitting with the electric response of a charge distribution which is a priori unknown Fig. 2.

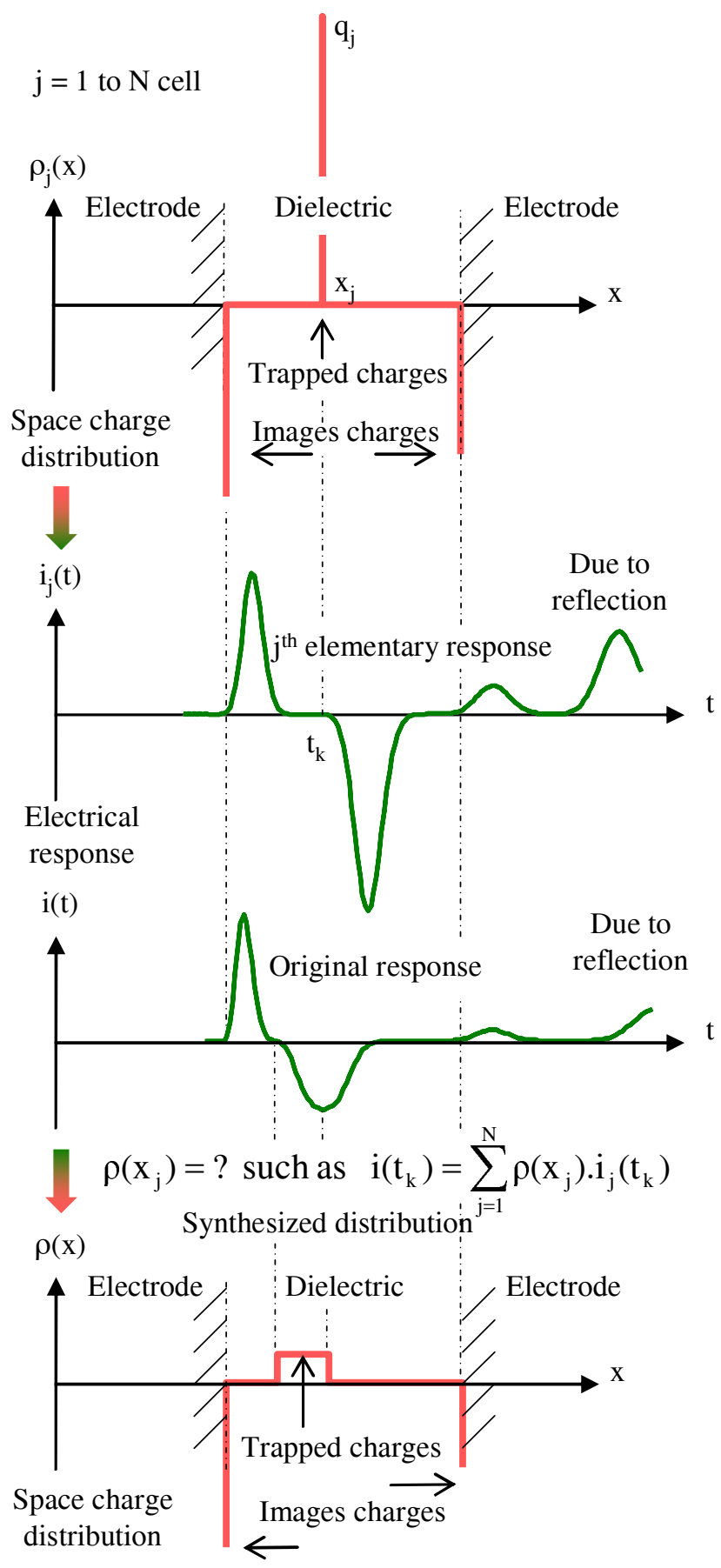

Fig. 2. Visual representation of adopted methodology allowing to synthesize the original charge distribution. 


\section{RESUlts}

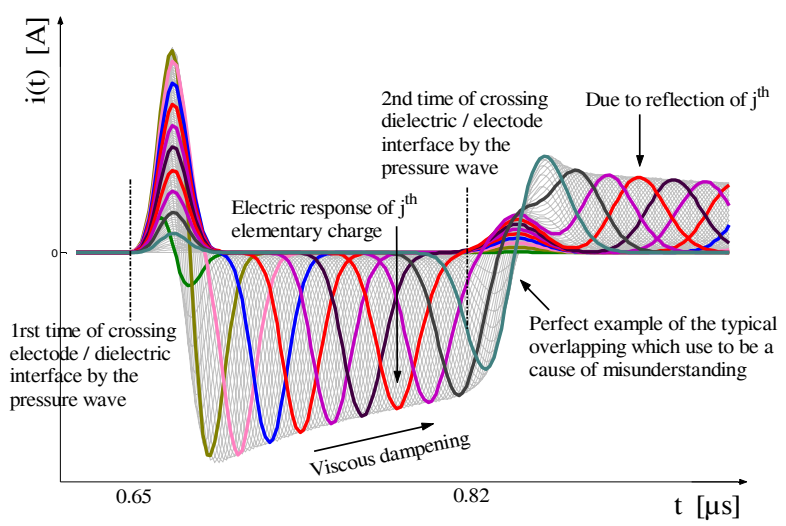

Fig. 3. The $\mathrm{N}$ elementary electrical responses due to the $\mathrm{N}$ elementary charge distribution. (cf annex for the understanding of acoustical reflections).

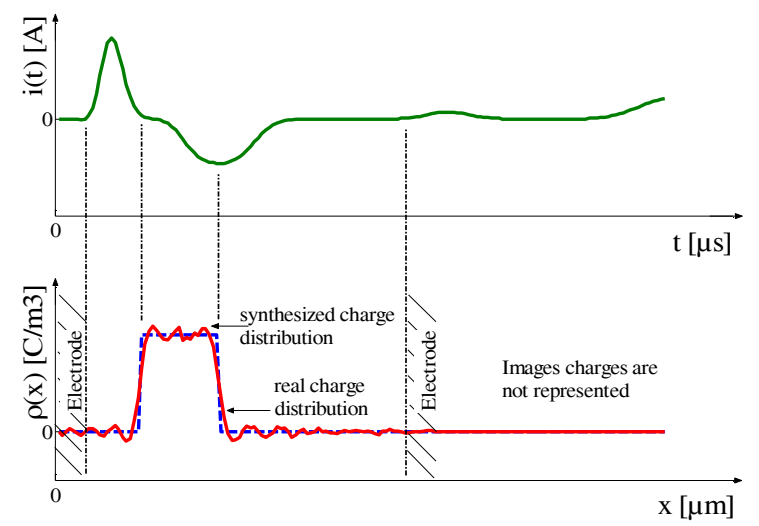

Fig. 4. Charge distribution synthesized from the top electrical response. Here the rank of matrix was voluntary limited (to $r=34$ ) to show how the synthesized distribution converge to the perfect solution (dashed line).

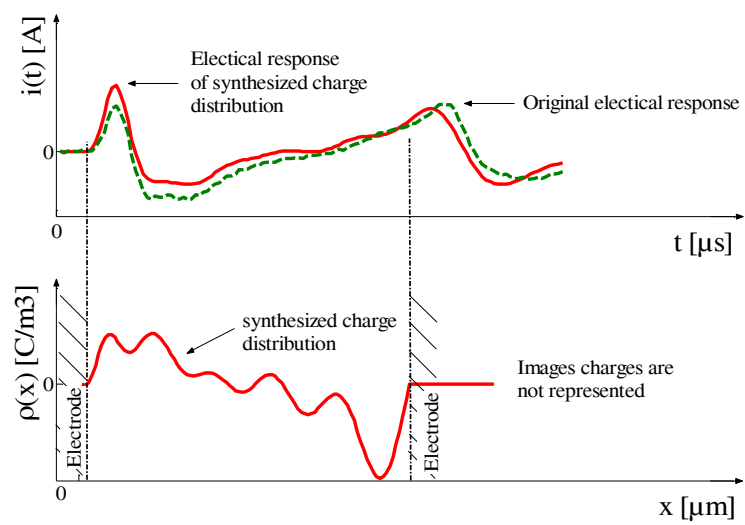

Fig. 5. Charge distribution synthesized from the top original electrical response (dashed line)

The above Fig. 3, 4 and 5 stands for summarize the main result of this study. Fig. 3 contains the $\mathrm{N}$ elementary electrical responses due to the $\mathrm{N}$ elementary charge distribution we need in order to resolve our linear problem. This figure is also a good way to feel the complex behaviour of electrical response, notably closed to the electrode. Fig. 4 permits to show how it's possible to synthesize perfectly the original charge distribution from an electrical response in condition to work with a, electro-mechanical model corresponding to the reality. Then Fig. 5 is the charge distribution synthesised from an original electric response (real). We show by this subsidiary result that synthesised charge distribution don't achieve a well fitting between the electrical response of synthesised charge distribution and the original electrical response.

\section{DISCUSSION}

When this method is tested within the framework of simulation, one manages perfectly to synthesize the original charge distribution, because the problem is simply linear. Calculation is of as much better than the rank of the elementary matrix of the answers is high. In practice this method has for vocation to replace the traditional techniques of deconvolution. However it comes out from these preliminaries experiment that the resolution of the problem depends primarily on the adequacy between the modelled object and the real object (real form of pressure wave, surface quality, homogeneousness, dampening, etc...). In the current state, the simplicity of our model does not answer this requirement and thus produces these numerical oscillations, characteristic of the problems of deconvolution which have also their limits.

\section{ACKNOWLEDGMENT}

Tanks are due to ESI Group for providing SYSTUS ${ }^{\circledR}$ Multiphysics Software.

\section{ANNEXE: CONCEPT Of ACOUSTIC IMPEDANCE}

When an acoustic wave meets the interface separating two mediums from different acoustic impedances, part of the wave is transmitted in the other medium while an other part is reflected on the interface Fig. 6. The concept of acoustic impedance makes it possible to study completely and quantitatively this phenomenon and to consider the quantities of acoustic transmitted and reflected energy.

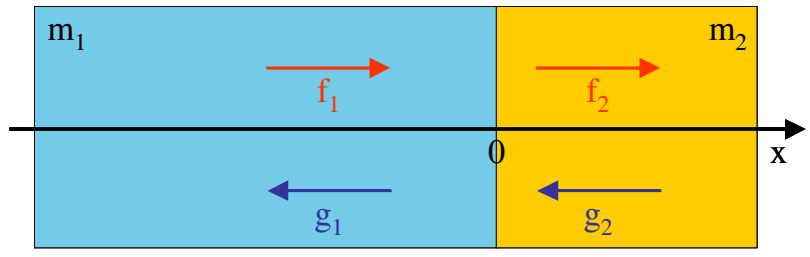

Fig. 6. Waves of normal incidences, waves considered and waves transmitted to the interface separating two acoustic mediums $\mathrm{m}_{1}$ and $\mathrm{m}_{2}$.

The study of the wave propagation to the interface of two acoustic mediums can be done at first approximation under the assumptions of no dispersive linear acoustics, and while being restricted with the waves of normal incidence to the interface. 
In this case, thermodynamics provides a linear constitutive relation between the efforts and the deformation (5) in which $\mathrm{x}$ is the variable of space following the normal direction to the interface, $p(x, t)$ is the acoustic pressure in the medium, $u(x, t)$ is the field of displacements, $\rho$ is the density of the medium, and $\mathrm{v}$ is the sound speed in the medium.

$$
p(x, t)=-\rho \cdot v^{2} \cdot \frac{\partial u(x, t)}{\partial x}
$$

The fundamental principle of dynamics applied locally to the medium and in the normal direction to the interface is written (6).

$$
\rho \cdot \frac{\partial \mathrm{v}(\mathrm{x}, \mathrm{t})}{\partial \mathrm{t}}=-\frac{\partial \mathrm{p}(\mathrm{x}, \mathrm{t})}{\partial \mathrm{x}}
$$

By noticing that $\mathrm{v}=\mathrm{du}(\mathrm{x}, \mathrm{t}) / \mathrm{dt}$, one can combine this equation with the constitutive law of linear acoustics to obtain the equation of the waves, also called Alembert equation, which is checked simultaneously by speed and the acoustic pressure ( 7 , 8).

$$
\begin{aligned}
& \frac{\partial^{2} v(x, t)}{\partial t^{2}}=v^{2} \cdot \frac{\partial^{2} v(x, t)}{\partial x^{2}} \\
& \frac{\partial^{2} p(x, t)}{\partial t^{2}}=v^{2} \cdot \frac{\partial^{2} p(x, t)}{\partial x^{2}}
\end{aligned}
$$

Speed $\mathrm{v}$ being solution of the equation of the waves, one can seek a solution of propagation in the form of the sum of a direct wave $f$ and a retrograde wave $g(9)$.

$$
v(x, t)=f(x-v . t)+g(x+v . t)
$$

Knowing that the acoustic pressure is also written it in the form of a solution of propagation, it is possible to identify it with the expression above, by introducing the acoustic impedance $\mathrm{Z}=\rho . \mathrm{v}(10)$.

$$
p(x, t)=Z[f(x-v . t)+g(x+v . t)]
$$

If one chooses the origin $\mathrm{x}=0$ with the interface between the two $\mathrm{m} 1$ mediums $=\{\mathrm{x}<0\}$, of acoustic impedance $Z_{1}$, and $m_{2}$ $=\{x>0\}$, of acoustic impedance $Z_{2}$, one can define the following restrictions: $f_{1}$ the restriction of the function of direct wave on $\mathrm{m}_{1} ; \mathrm{g}_{1}$ the restriction of the function of retrograde wave on $\mathrm{m}_{1} ; \mathrm{f}_{2}$ the restriction of the function of direct wave on $\mathrm{m}_{2} ; \mathrm{g}_{2}$ the restriction of the function of retrograde wave on $\mathrm{m}_{2}$. In $\mathrm{x}=0$, the condition of continuity speeds and pressures are written $(11,12)$.

$$
\begin{aligned}
& f_{1}(-v . t)+g_{1}(v . t)=f_{2}(-v . t)+g_{2}(v . t) \\
& Z_{1}\left[f_{1}(-v . t)-g_{1}(v . t)\right]=Z_{2}\left[f_{2}(-v . t)-g_{2}(v . t)\right]
\end{aligned}
$$

If one gives oneself the direct wave coming from the left $f_{1}$ and the retrograde wave coming from the right-hand side $\mathrm{g}_{2}$, one can deduce the transmitted $\mathrm{f}_{2}$ and reflected waves from them $\mathrm{g}_{1}(13)$.

$$
\left(\begin{array}{l}
\mathrm{f}_{2} \\
\mathrm{~g}_{1}
\end{array}\right)=\frac{1}{Z_{1}+Z_{2}}\left(\begin{array}{cc}
Z_{2}-Z_{1} & 2 . Z_{1} \\
2 . Z_{2} & Z_{1}-Z_{2}
\end{array}\right)\left(\begin{array}{l}
\mathrm{g}_{2} \\
\mathrm{f}_{1}
\end{array}\right)
$$

In this matrix, the elements have the following physical significance $(14,15,16,17)$ :

$$
\mathrm{t}_{12}=\frac{2 \cdot \mathrm{Z}_{1}}{\mathrm{Z}_{1}+\mathrm{Z}_{2}}
$$

is the coefficient of transmission in amplitude of the waves since $\mathrm{m}_{1}$ towards $\mathrm{m}_{2}$;

$$
\mathrm{r}=\frac{\mathrm{Z}_{1}-\mathrm{Z}_{2}}{\mathrm{Z}_{1}+\mathrm{Z}_{2}}
$$

is the coefficient of reflection in amplitude of the waves coming from $\mathrm{m}_{1}$ on the interface;

$$
-r=\frac{Z_{2}-Z_{1}}{Z_{1}+Z_{2}}
$$

is the coefficient of reflection in amplitude of the waves coming $\mathrm{m}_{2}$ on the interface;

$$
\mathrm{t}_{21}=\frac{2 . \mathrm{Z}_{2}}{\mathrm{Z}_{1}+\mathrm{Z}_{2}}
$$

is the coefficient of transmission in amplitude since $\mathrm{m}_{2}$ towards $\mathrm{m}_{1}$. These coefficients are similar to those given by the formulas of Fresnel in electromagnetism [4].

\section{REFERENCES}

[1] O. Gallot-Lavallée, J.L. Reboud, P. Rain, "Multiphysics simulation to improve the understanding of Pressure Wave Propagation techniques applied to composite polymers", IEEE CEIDP, , pp. 61-64, Oct. 2006.

[2] S. Hole, A. Sylvestre, O. Gallot-Lavallée, C. Guillermin, P. Rain, S. Rowe, "Space charge distribution measurement methods and particle loaded insulating materials", Journal of Physics D (Applied Physics), vol.39, no.5, pp. 950-6, Mar. 2006.

[3] R. Gerhard-Multhaupt, "Analysis of pressure-wave methods for the nondestructive determination of spatial charge or field distributions in dielectrics", Physical Review B, vol. 27, pp. 2494-2503, Feb. 1983.

[4] C. Lesueur, "Rayonnement acoustique des structures", Eyrolles, Paris, 1988.

Author address: olivier.gallot-lavallee@ grenoble.cnrs.fr G2Elab Dielectric Team: http://www-lemd.grenoble.cnrs.fr/ 